\title{
Social inequality and child malnutrition in four Andean countries
}

\author{
Carlos Larrea ${ }^{1}$ and Wilma Freire ${ }^{2}$
}

ABSTRACT Objective. To analyze the effects of socioeconomic, regional, and ethnic conditions on chronic malnutrition in four Andean countries of South America: Bolivia, Colombia, Ecuador, and Peru.

Methods. The study was based on Demographic and Health Surveys (DHS) for Colombia (1995), Peru (1996), and Bolivia (1997), and on a Living Standard Measurement Survey for Ecuador (1998). We developed an index of household socioeconomic status using categorical principal components analysis. We broke down the prevalence of stunting by socioeconomic status (SES), ethnicity, place of residence (large cities, small cities, towns, and countryside), and region (highland region versus other areas of the country). We applied smoothed regression curves and linear functions to analyze SES effects on stunting, with specific models for Bolivia, Ecuador, and Peru.

Results. Bolivia, Ecuador, and Peru have similar characteristics, with high stunting prevalences overall; higher stunting prevalences in their highland areas, particularly among indigenous populations; and strong socioeconomic disparities. Colombia, in contrast, has a lower stunting prevalence and smaller regional disparities. The socioeconomic gradient of stunting is strong in all four countries, with prevalence rates in the poorest deciles at least three times as high as those in the top decile.

Discussion. The sharp contrast between the conditions found in Bolivia, Ecuador, and Peru and those in Colombia may be the result of specific ethnic factors affecting indigenous groups; a particular diet profile in the highland areas, with low protein and micronutrient intake; and differences in the long-term economic and social development paths that the countries have taken. Along with the strong socioeconomic gradient in all the countries, the weight of ethnic and regional factors suggests the need to reduce inequality as well as to comprehensively improve education and housing, better target health and nutrition programs, and implement participatory programs integrated into indigenous cultures.

Key words Equity, malnutrition, nutritional status, poverty, socioeconomic factors.

This article analyzes empirical evidence from recent household surveys

\footnotetext{
1 Facultad Latinoamericana de Ciencias Sociales Sede Ecuador, Quito, Ecuador, and Harvard Center for Society and Health, Boston, Massachusetts, United States of America. Send correspondence to: Carlos Larrea; e-mail: carlarr@uio.satnet.net

2 Food and Nutrition Program, Pan American Health Organization, Washington, D.C., United States of America.
}

on chronic malnutrition and its relation to social, regional, and ethnic disparities in four Andean countries of South America: Bolivia, Colombia, Ecuador, and Peru.

There are two immediate causes of chronic child malnutrition (extremely low height-for-age): insufficient access to nutrients and high disease exposure. However, socioeconomic, re- gional, and ethnic factors frequently play a significant role in nutritional outcomes.

While malnutrition has generally been declining in recent decades, it is still a severe problem, affecting at least $27 \%$ of children younger than 5 years of age in the developing world and $21 \%$ of the children under 5 in the four Andean countries of our study (1-4). 
Poverty and social inequality are pervasive in the Andean nations, and in recent years the prospects for social development there have been affected by economic crisis, social conflict, and political instability $(5,6)$.

Child malnutrition has generally declined in Latin American countries over the last several decades as socioeconomic conditions have improved and fertility levels have declined. Nevertheless, such progress has been slow, poverty and social inequality are still widespread, and malnutrition prevalence rates remain high in many countries, including several of the Andean countries in our study.

Although the association between poverty and malnutrition is generally well-known, more empirical and analytical work is still needed on the relationships between social inequality and malnutrition within Latin American countries. In fact, concerns about health and equity are becoming more prominent, and specific policies to promote nutrition among the poor have been called for.

\section{INFORMATION SOURCES AND STUDY METHODOLOGY}

Our study is based on household surveys that were done in the midand late-1990s and that included anthropometric measures on children younger than 5 years. Demographic and Health Surveys (DHS) were the main sources of data for Colombia (a survey done in 1995), Peru (1996), and Bolivia (1997), with a Living Standard Measurement Survey (LSMS) providing the information for Ecuador (1998). All those surveys had national coverage, representative sample sizes, and detailed questionnaires on socioeconomic conditions, access to health services, and maternal and health outcomes (7-10).

Conventionally, children's anthropometric measures are transformed to a normalized scale of $z$ scores of height-for-age, weight-for-age, and height-for-weight. A child is affected by chronic malnutrition (stunting) when his or her $z$ score of height-for-

TABLE 1. Indicators for education, housing, and employment that make up the three dimensional indices and the global index of socioeconomic status (SES), study of child malnutrition in four Andean countries ${ }^{a}$

\begin{tabular}{ll}
\hline \multicolumn{1}{c}{ Indicator } & Dimensional index \\
\hline Education & Education index \\
1A. Illiteracy among persons older than 14 years & \\
1B. Years of schooling among persons older than 23 & \\
1C. Access to higher education among persons older than 23 & \\
1D. Primary school attendance rate & Housing index \\
1E. Secondary school attendance rate & \\
1F. Post-secondary attendance rate & \\
Basic housing conditions & \\
2A. Source of drinking water & Housing index \\
2B. Type of toilet facility & \\
2C. Main material of the floor & \\
2D. Number of bedrooms per person & \\
2E. Does the household have electricity? & \\
2F. Square root of time spent to get water & \\
Household assets & \\
2G. Does the household have a radio? & \\
2H. Does the household have a television? & \\
2I. Does the household have a refrigerator? & \\
2J. Does the household have a telephone? & \\
2K. Does any member of the household own a car? & \\
2L. Does any member of the household own a bicycle? & \\
Employment & \\
3A. Years of formal schooling of women aged 15-49 & \\
3B. Years of formal schooling of women's husband/partner & \\
3C. Occupational group of women aged 15-49b & \\
3D. Occupational group of women's husband/partnerb & \\
3E. Occupational category of women aged 15-49b & \\
3F. Women's time spent working in the last 12 months & \\
\hline
\end{tabular}

a Education indicators were household averages from applicable individuals. The education index was estimated using principal components analysis, given that all indicators were numerical. The housing and employment indices were estimated using categorical principal components analysis, combining all the respective indicators listed in Table 1. The global SES index was estimated by combining the education, housing, and employment indices, using principal components analysis.

b The occupational group has an ordinal scale according to the skills of the job, while the occupational category differentiates among wage earners, independent workers, and persons without paid employment.

age is lower than -2 , or two standard deviations, below the international normalized median. Using the same criterion, global malnutrition is defined by low weight-for-age scores, and acute malnutrition corresponds to low height-for-weight.

Both global malnutrition and acute malnutrition may reflect occasional weight loss as a result of recent disease episodes. Stunting, however, is more representative of insufficient growth due to persistent dietary deficiencies and/or susceptibility to illness. This paper takes chronic malnutrition and its associated height-for-age $z$ score as indicators of nutritional status.

DHS surveys have common questionnaires, allowing the development of multivariate indices for different countries. For our study of the four Andean nations we established an integrated socioeconomic status (SES) index that included three dimensions: education, housing, and employment.

Each dimension, in turn, derives from a particular set of indicators, as shown in Table 1. We applied categorical principal components analysis to develop multivariate indices of education, housing, and employment from the indicators, and then we estimated a global SES index from those three dimensional indices. The procedure permits the integration of both numerical and categorical variables, and it is a generalized extension of the classical method of principal components, which was originally restricted to just numerical variables. 
Most of the questions in DHS surveys and other household surveys, as well as an important part of the social indicators (such as the household source of drinking water, or the occupational group), are categorical variables, either nominal or ordinal. $\mathrm{Nu}$ merical indicators alone, such as years of schooling or the time spent to get drinking water, are usually insufficient for summarizing the questionnaire's most relevant topics.

As a statistical procedure, the categorical principal components analysis (CATPCA) simultaneously provides optimal quantification of categorical variables and reduces the dimensionality of the data, by summarizing in a reduced number of factors most of the information provided by the original indicators (11-14). CATPCA handles nominal, ordinal, and numeric indicators. An index (based on the first principal component) may be interpreted as the linear combination of constituent indicators, which captures the maximum possible amount of information provided by the indicators. The index optimizes the explained proportion of the total original indicator variance. While this paper emphasizes our findings, a detailed explanation of the methodology applied in this research is also available. ${ }^{3}$

In the particular case of Ecuador, where the LSMS is the only household survey with child anthropometric measures from the 1990s, no multivariate indices were estimated. For comparative analysis, aggregate per capita consumption is used as a proxy for the SES index. (Aggregate per capita consumption is the total household consumption divided by the number of household members. A regional price index was used to compensate for local differences in the cost of living.) Aggregate consumption is regarded as a more reliable and stable indicator of SES than household income, which has short-term fluctuations and is frequently underreported.

\footnotetext{
Larrea C. Inequidad social, salud reproductiva y nutrición en ocho países de América Latina: análisis comparativo de las Encuestas DHS III [unpublished paper]. Washington D.C.: Pan American Health Organization; 2000.
}

Bolivia, Ecuador, and Peru have significant indigenous populations, with their own cultures and languages. Although the DHS and LSMS surveys do not include a direct question concerning race or ethnicity, they each have a question about the language spoken at home. If the answer included an indigenous language, the household was identified as indigenous. Although this procedure may underestimate the size of indigenous groups, it is useful for identifying ethnic differences.

We prepared descriptive data on stunting prevalence by place of residence (large cities vs. small cities, etc.), geographic region (highland region vs. other areas of a country), ethnicity, and SES. We also calculated an estimate of the socioeconomic gradient in stunting as well as concentration indices (concentration indices are widely used indicators of social inequality in health and are based on a generalization of the Gini coefficient) (1). In addition, we conducted a specific regional analysis for the three Andean countries with severe geographical disparities, where we prepared separate regressions for the highland area of each country and for the other regions in the same country. Both linear regression models and smoothed regression curves were estimated in each case.

\section{RESULTS}

\section{The regional, ethnic, and socio- economic distribution of stunting in the four Andean countries}

The Andean countries have persistently suffered from pronounced social, regional, and ethnic inequality as well as widespread poverty, with economic and social indicators falling below the averages for Latin America as a whole. Further, in the Andean countries over the last two decades, the economic achievements from structural adjustment programs and export promotion efforts have been weak, social conflict has been growing, and various forms of political violence have emerged.

The Andean countries, however, are internally diverse and heterogeneous.
In broad terms, Colombia has historically achieved significant and more stable economic growth rates, coupled with efficient industrialization and diversification. On the other hand, Bolivia, Ecuador, and Peru remain less diversified economically, with lower per capita incomes. Those three countries also have deeper ethnic and regional disparities, which have shaped their societies from the colonial period. Table 2 presents basic economic and social indicators for the four Andean countries of this study.

Table 3 presents stunting prevalence for each of the four countries, broken down by place of residence, ethnicity, region, and SES. In Bolivia, Ecuador, and Peru, the historic development of the Inca Empire and other indigenous civilizations took place mostly in the Andean highlands (the altiplano high plateau, in the case of Bolivia). During the colonial period (from the 1530s to the 1820s), an important fraction of both the indigenous population and the white elite remained concentrated in the highland/altiplano areas, with the exception of the city of Lima, Peru, which is located on the Pacific coast. Most of the migration to the lowlands of the coast or other tropical lands took place during the republican period, particularly from the late nineteenth century to the present, as an outcome of export expansion, urbanization, and economic diversification. As a result, most of the deprived indigenous population still live in the highlands, where traditional social structures prevail. Consequently, in general for a particular country, a defined geographic difference exists between this highland region and the other, nonhighland areas of the rest of the country. Colombia, however, has a different regional configuration, as the Andean mountains there split into two divergent chains, and its indigenous population is smaller and culturally less defined.

In Bolivia, Ecuador, and Peru the national prevalence of chronic malnutrition is high, around $26 \%$ to $27 \%$, while Colombia has a notably lower rate of $15 \%$ (Table 3 ). Among the eight countries of Latin America and the 
TABLE 2. Basic economic and social indicators (1999) for four Andean countries vs. Latin America and the Caribbean overall

\begin{tabular}{|c|c|c|c|c|c|}
\hline Country/Region & HDI rank ${ }^{\mathrm{a}}$ & HDI value ${ }^{b}$ & $\begin{array}{c}\text { GDP per } \\
\text { capita (US\$) }\end{array}$ & $\begin{array}{l}\text { Infant mortality } \\
\text { rate per } 1000\end{array}$ & $\begin{array}{l}\text { Public health expenditure } \\
\qquad(\% \text { GDP }), 1998^{d}\end{array}$ \\
\hline Colombia & 62 & 0.765 & 5749 & 26 & 5.2 \\
\hline Peru & 73 & 0.743 & 4622 & 42 & 2.4 \\
\hline Bolivia & 104 & 0.648 & 2355 & 64 & 4.1 \\
\hline \multicolumn{6}{|l|}{ Latin America and } \\
\hline the Caribbean overall & $N A^{e}$ & 0.760 & 6880 & 32 &.$^{\dagger}$ \\
\hline
\end{tabular}

Data source: Reference 15.

${ }^{a} \mathrm{HDI}$ rank = Ranking of countries according to Human Development Index of the United Nations Development Program (UNDP), from best (1) to worst (162).

${ }^{b} \mathrm{HDI}$ value = UNDP Human Development Index value. Values range from 0 (worst) to 1.0 (best). The value is based on three aspects of human development: longevity (measured by life expectancy at birth), knowledge (measured by a combination of the adult literacy rate and the combined gross primary, secondary, and tertiary enrollment ratio), and standard of living (measured by gross domestic product per capita).

${ }^{c}$ The gross domestic product (GDP) per capita is given in purchasing power parity (PPP) US\$; the PPP factor corrects for national differences in the cost of living

${ }^{d}$ Public health expenditures are given as a percentage of gross domestic product (GDP).

${ }^{\mathrm{e}} \mathrm{NA}=$ not applicable.

f The ellipsis symbol (. . .) indicates that the data were not available.

TABLE 3. Stunting prevalence among children (\%) by country, place of residence, ethnicity, region, and socioeconomic status (SES), four Andean countries

\begin{tabular}{|c|c|c|c|c|}
\hline & \multicolumn{4}{|c|}{ Country } \\
\hline & Colombia & Ecuador & Peru & Bolivia \\
\hline \multicolumn{5}{|l|}{ Place of residence ${ }^{a}$} \\
\hline Large cities & 12.7 & 20.7 & 13.2 & 18.5 \\
\hline Small cities & 10.9 & 22.4 & 20.1 & 20.3 \\
\hline Towns & 14.0 & 28.2 & 27.2 & 22.4 \\
\hline Countryside & 19.3 & 35.2 & 40.8 & 37.2 \\
\hline \multicolumn{5}{|l|}{ Ethnicity } \\
\hline Nonindigenous & $\mathrm{b}$ & 24.2 & 22.5 & 23.7 \\
\hline Indigenous & $\ldots$ & 58.2 & 47.0 & 50.5 \\
\hline \multicolumn{5}{|l|}{ Region } \\
\hline Highland or altiplano & $\ldots$ & 33.3 & 38.5 & 31.2 \\
\hline Other regions & $\ldots$ & 22.2 & 18.2 & 23.9 \\
\hline \multicolumn{5}{|l|}{ Deciles of SESc } \\
\hline 1 (lowest) & 26.8 & 38.5 & 49.6 & 42.2 \\
\hline 2 & 24.1 & 51.8 & 46.8 & 39.9 \\
\hline 3 & 17.1 & 30.6 & 39.6 & 38.7 \\
\hline 4 & 14.9 & 27.6 & 32.5 & 32.8 \\
\hline 5 & 16.3 & 27.9 & 23.4 & 31.8 \\
\hline 6 & 15.2 & 24.4 & 19.9 & 25.0 \\
\hline 7 & 11.0 & 19.0 & 18.3 & 22.7 \\
\hline 8 & 11.7 & 19.1 & 12.8 & 18.2 \\
\hline 9 & 6.3 & 15.8 & 12.6 & 13.5 \\
\hline 10 (highest) & 5.4 & 11.9 & 5.2 & 9.7 \\
\hline Concentration index ${ }^{d}$ & -0.221 & -0.223 & -0.311 & -0.223 \\
\hline Overall country prevalence & 14.9 & 26.5 & 26.1 & 26.9 \\
\hline
\end{tabular}

Caribbean with DHS III surveys (Bolivia, Brazil, Colombia, the Dominican Republic, Guatemala, Haiti, Nicaragua, and Peru), only two of them have worse conditions than do Bolivia,
Ecuador, and Peru: Guatemala $(46 \%$ chronic malnutrition in 1998) and Haiti $(32 \%$ in 1994) $(16,17)$.

Urban-rural differences are extremely high in Peru, with a rural chronic mal- nutrition prevalence about three times as high as that of Lima. Both Bolivia and Ecuador also have large urban-rural differences. Colombia, in contrast, has a relatively low pattern of disparity, with 
a 1.5 ratio between the rates in the rural areas and in the large cities.

The ethnic divide is striking in Bolivia, Ecuador, and Peru (Table 3). In all three cases, prevalence among indigenous peoples is more than twice that of the rest of society. Similarly, the highland region of each of the three countries has a prevalence rate that is substantially above the rate in the lowland areas of the respective country.

Regional disparities in Colombia (not presented in Table 3) are smaller and not statistically significant at the 5\% level. The DHS survey of Colombia defines five main regions, and none of them departs more than 3 percentage points from the national average of $14.9 \%$. The Pacific region of Colombia has the country's highest stunting rate, $17.3 \%$, while the central region has the lowest, $13.2 \%$. Even at the smaller, departmental level, Colombia has only one outlier. That is the southwestern department of Nariño, which borders the highland area of neighboring Ecuador and has a prevalence of 35\% (Nariño's DHS sample had 158 valid cases, a relatively small number).

From a socioeconomic perspective, the malnutrition patterns are less clearly defined. Peru has the strongest association between stunting and social inequality, due to both its concentration index $(-0.31)$ and its extreme ratio (9.5 to 1) between stunting in the highest and lowest deciles (Table 3). (A high concentration index value indicates a strong association between social inequality and stunting.) Bolivia, Colombia, and Ecuador have lower levels of socioeconomic inequality in stunting. Later in this article we will analyze why the socioeconomic patterns in the four countries are less clearly defined than are the other results. As these descriptive data suggest, specific regional or ethnic differences may be blurred in national socioeconomic gradients.

\section{The socioeconomic gradient in child malnutrition}

There is growing evidence linking health and socioeconomic status, both in industrialized and developing coun-

FIGURE 1. Stunting among children (\%) by percentiles of socioeconomic status (SES) for four Andean countries

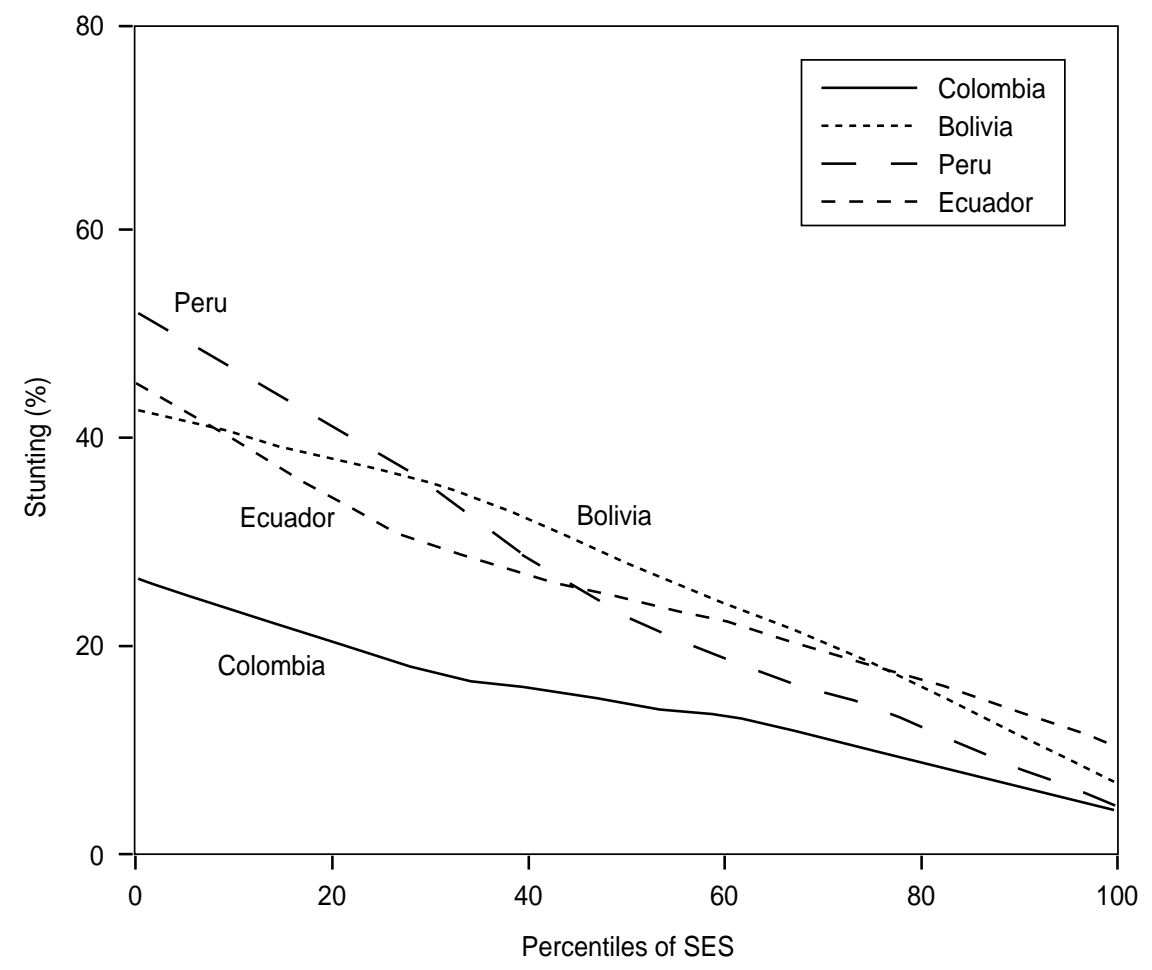

Sources: Macro International (7-9) and World Bank (10).

tries (18). Given that, it is worth exploring the size and shape of the gradient between SES and stunting in the four Andean countries of our study and also in the various regions within those countries.

As shown in Figure 1, all four countries follow a clear linear trend. That figure presents the calculated smoothed locally weighted regression curve (LOWESS regression), based on average stunting estimates for each percentile of SES for the countries. Bolivia, Ecuador, and Peru each has a high gradient, with a linear slope ranging from -0.35 in Ecuador to -0.49 in Peru. Colombia has the lowest gradient, with a slope of -0.22 . ("High" and "low" refer to absolute values, without regard to the negative sign of the slopes.)

Hypothetically, at least two factors could explain the difference between Colombia and the three other countries. One possibility is per capita income. Colombia's per capita income is the highest of the four nations. Child malnutrition is often the result of poverty and of underconsumption and inadequate access to protein and micronutrients. Higher per capita incomes are linked with reduced poverty and better access to food and basic goods, even in the highly inegalitarian situation found in these four Andean countries.

The argument concerning income, however, fails to explain all the results of our study. For example, malnutrition prevalence is very similar in Bolivia and Peru, in spite of the fact that the per capita income is twice as high in Peru.

There is a second possible explanation for the differences between Colombia and the three other Andean countries of our study: divergent longterm development patterns. Rosemary Thorp has compared the process of social transformation, institutionbuilding, and economic growth in Peru and Colombia, from the midnineteen century to the present (19). 
According to Thorp, the two countries followed very different paths and achieved very different results. In Colombia, the different regions of the country were more similar in their economic growth. This was due to the way in which the coffee economy and other export sectors developed, as well as patterns in land ownership and foreign investment in the country. Colombia developed a stronger institutional capacity in the public sector, leading to a more stable and decentralized process of economic growth. Social expenditure has been stronger and more efficient in Colombia, resulting in higher education levels and lower rates of infant mortality than in Peru. Peru was affected by an extreme regional concentration of wealth in Lima and lower efficiency in public institutions. These patterns resulted from specific traits of the historical development of exports of guano, sugar, copper, and oil, and they led to weaker social and geographical diffusion of economic growth. Nevertheless, there was an overall weakness of social development in both countries, according to Thorp (19). Viewed from a broader perspective, her argument suggests the importance of human and institutional factors such as education, transparency, decentralization, and good governance.

\section{The highland regions versus other areas}

The socioeconomic effect, however, explains only a part (albeit a significant one) of the differences in child malnutrition found in the four Andean countries of our study. To analyze regional effects more closely, Figure 2 explores regional SES-stunting functions, differentiating between the highland area and the other regions of the country for Bolivia, Ecuador, and Peru. Regional inequalities in Colombia are small and thus are not plotted.

Figure 2 shows clearly that there is a higher stunting prevalence in the highland area than in the remaining regions of each of the countries. For a given national socioeconomic level,

FIGURE 2. Stunting among children (\%) by percentiles of socioeconomic status (SES) and regions within three Andean countries

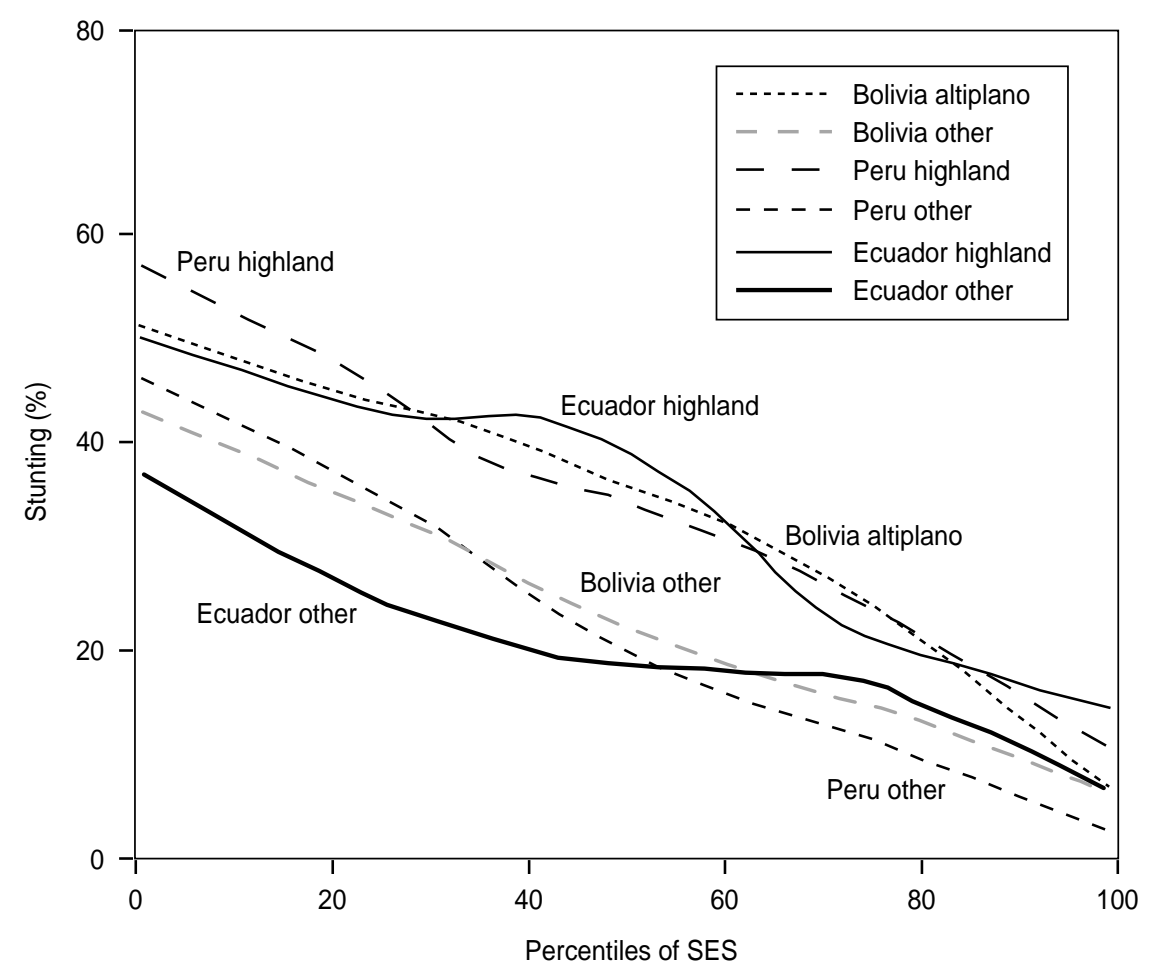

Sources: Macro International (8, 9) and World Bank (10).

the predicted stunting rate in the highland region of a country is about $10 \%$ higher than the rates in the other parts of the same country. The slopes, however, are similar for all the curves.

Table 4 provides a detailed analysis of linear regression models for Bolivia, Ecuador, and Peru. In all three countries there is a statistically significant difference in the intercept between the highland region and the other regions of the country, at the 5\% significance level. Slope differences, on the other hand, are rather small.

Regional differences in stunting prevalence exist in Ecuador, Peru, and Bolivia, in addition to the socioeconomic gradient. In all three countries, highland prevalence rates are about $10 \%$ higher than those of the other regions.

A recent country study of Ecuador provides an explanatory hypothesis for these regional differences within each country. An analysis of apparent food consumption reported in the
LSMS survey showed that poor rural households in the highland area have a diet mostly based on carbohydrates from potatoes and flour, with insufficient intakes of protein and micronutrients (20). In contrast, in Ecuador's coastal and Amazon basin regions, fish and other protein sources are important components of the diet even in poor households.

A multiple regression model presented in the same study (20) identifies four social determinants of stunting. Two of those factors are socioeconomic: aggregate per capita consumption and mother's educational level. In addition, there are ethnic and regional effects, with risks being higher for indigenous households and for highland households.

\section{An international SES index}

National percentiles of SES are specific to each country and do not permit 
TABLE 4. Linear regression models for stunting and socioeconomic status by country and region, for Bolivia, Ecuador, and Peru ${ }^{a}$

\begin{tabular}{|c|c|c|c|c|c|c|c|c|c|c|}
\hline \multirow[b]{3}{*}{ Country/Region } & \multirow[b]{3}{*}{ Intercept } & \multicolumn{4}{|c|}{ Intercept } & \multicolumn{4}{|c|}{ Slope } & \multirow[b]{3}{*}{$r^{2}$} \\
\hline & & \multirow[b]{2}{*}{$\begin{array}{l}\text { Standard } \\
\text { error }\end{array}$} & \multirow[b]{2}{*}{$\begin{array}{c}P \\
\text { value }\end{array}$} & \multicolumn{2}{|c|}{$95 \%$ confidence interval } & \multirow[b]{2}{*}{ Slope } & \multirow[b]{2}{*}{$\begin{array}{c}P \\
\text { value }\end{array}$} & \multicolumn{2}{|c|}{$95 \%$ confidence interval } & \\
\hline & & & & $\begin{array}{l}\text { Lower } \\
\text { bound }\end{array}$ & $\begin{array}{l}\text { Upper } \\
\text { bound }\end{array}$ & & & $\begin{array}{l}\text { Lower } \\
\text { bound }\end{array}$ & $\begin{array}{l}\text { Upper } \\
\text { bound }\end{array}$ & \\
\hline \multicolumn{11}{|l|}{ Ecuador } \\
\hline Highland & 50.27 & 2.552 & $<0.0001$ & 45.21 & 55.34 & -0.353 & $<0.0001$ & -0.442 & -0.265 & 0.40 \\
\hline Other regions & 39.78 & 3.620 & $<0.0001$ & 32.59 & 46.96 & -0.335 & $<0.0001$ & -0.457 & -0.213 & 0.23 \\
\hline Other regions & 43.34 & 1.667 & $<0.0001$ & 40.03 & 46.65 & -0.430 & $<0.0001$ & -0.482 & -0.378 & 0.74 \\
\hline \multicolumn{11}{|l|}{ Bolivia } \\
\hline Altiplano & 52.80 & 2.149 & $<0.0001$ & 48.54 & 57.06 & -0.398 & $<0.0001$ & -0.470 & -0.326 & 0.55 \\
\hline Other regions & 42.76 & 1.578 & $<0.0001$ & 39.62 & 45.89 & -0.375 & $<0.0001$ & -0.429 & -0.320 & 0.65 \\
\hline
\end{tabular}

Data sources: References 8,9 , and 10.

${ }^{a}$ In this analysis the independent variable is socioeconomic status percentile, and the dependent variable is stunting

international comparisons of living conditions. For example, Colombian children have better social indicators than do their Bolivian counterparts in the same percentiles.

In order to compare data across countries, we developed an internationally comparable SES index from DHS III surveys in eight Latin American countries: Bolivia, Brazil, Colombia, the Dominican Republic, Guatemala, Haiti, Nicaragua, and Peru. Our index makes it possible to analyze the effect of absolute changes in living conditions on stunting. The resulting LOWESS curves for three of the Andean countries are plotted in Figure 3.

Curvilinear effects are visible in the figure, with different slopes for different SES levels. The curves follow a logistic-function path, with the slopes generally being steeper in the curves' first half than they are in their second half. This pattern suggests steeper relationships between SES and stunting at low to medium levels of economic development. However, the very poorest households have slightly lower slopes, so the initial reductions in stunting, for given socioeconomic improvements, will be comparatively small. In general, the reductions in stunting coming from SES improvements depend on socioeconomic level, with the benefits of reduced stunting being strongest among poor to medium-status house- holds and then flattening out among better-off households.

The gradient in Colombia remains flatter than for the two other countries. Even comparing similar living standards, malnutrition rates in Colombia are lower than those in Bolivia and Peru. Both the intercept and the gradient seem different. This finding supports the hypothesis that, in addition to differences in absolute living conditions, Colombia's nutritional profile is better than that of its counterparts. Among the factors that might explain the differences are a consistently higher long-term investment in education and health, a more balanced regional economic configuration, and more efficient public policies.

\section{DISCUSSION}

The stunting rates in the four Andean countries of our study rank among the worst in Latin America and the Caribbean, being surpassed only by Guatemala and Haiti, in the group of countries with available information from DHS surveys. Lower SES was associated with stunting in all four of the Andean countries. Bolivia, Ecuador, and Peru have steeper gradients than Colombia does. The difference is only partially explained by economic factors, and the influence of consis- tently more efficient public sector performance as well as higher social expenditures in Colombia is suggested.

The explanatory factors for national, regional, and ethnic differences in child malnutrition need to explored further. Of particular importance would be a closer examination of the social and ethnic determinants of stunting as well as their contributions to achieving nutritional improvements.

In the four countries analyzed, and particularly in Bolivia, Ecuador, and Peru, malnutrition remains widespread. It contributes to the intergenerational perpetuation of poverty and inequality and limits prospects for human development.

The strong socioeconomic gradient in stunting confirms the need to reduce inequality and to focus resources on the poor, instead of working only to reduce the national averages without regard to the social distribution of the improvements. Moreover, the concavity of the SES-stunting function (Figure 3) suggests there will be higher returns for social investments made among those who belong to the poor and middle social strata.

The steep SES gradient confirms the strategic importance of education, housing, and employment as elements of policies aimed at improving nutrition. Rather than operating in isolation, health programs should be inte- 
FIGURE 3. Stunting among children (\%) by index of socioeconomic status (SES) for three Andean countries

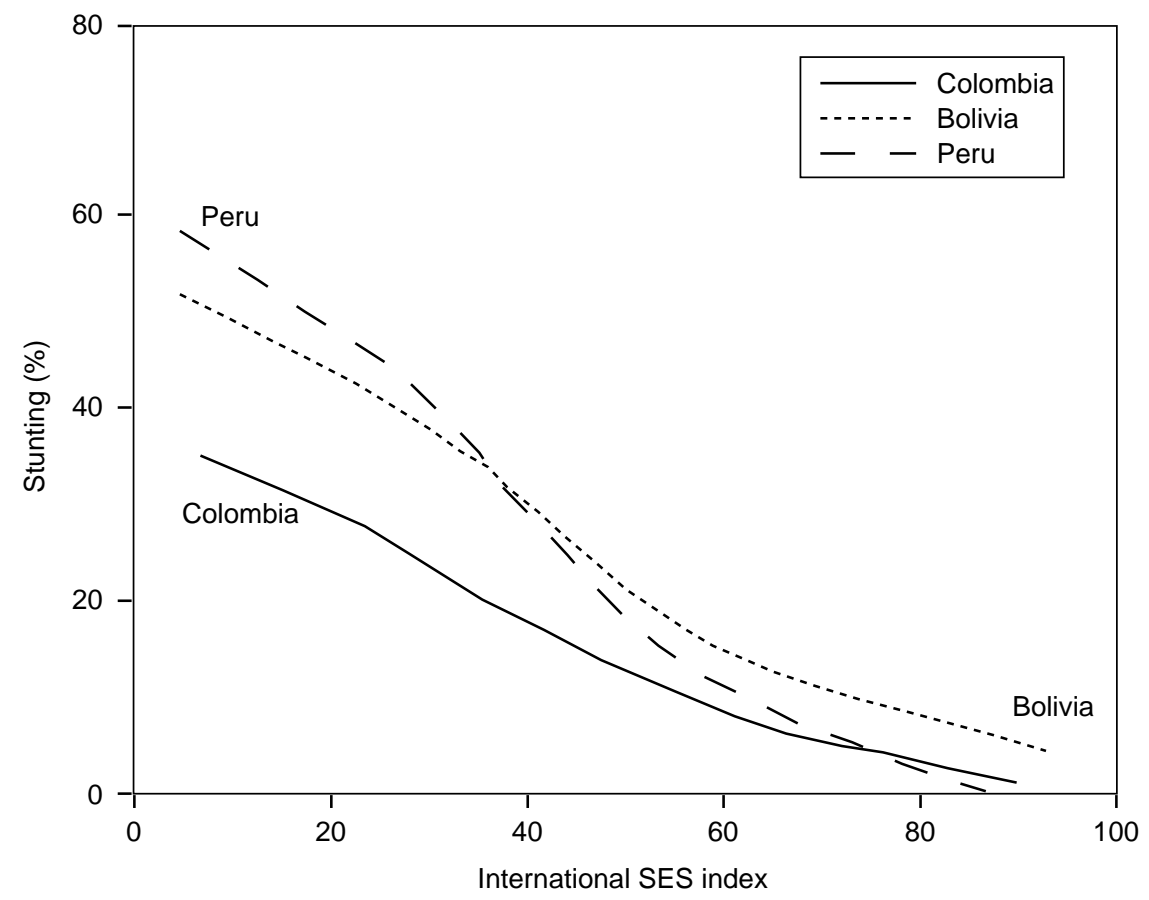

Sources: References 7-9. gral components of comprehensive social policies. The Colombian experience suggests the long-term importance of institutional factors as well as the returns that can come from sustained social and health investment.

The effects of specific regional or ethnic factors in Bolivia, Ecuador, and Peru might be reduced by better targeting resources to the deprived rural highlands regions. Another remedy might be to implement participatory programs integrated into the fabric of indigenous cultures. Further, enriching the diet of persons in highland regions could help in the development of those areas.

Acknowledgments. The authors would like to acknowledge the academic contribution and valuable comments of Dr. Ichiro Kawachi to this paper as well as the institutional research support from the Harvard Center for Society and Health and from the Pan American Health Organization.

\section{REFERENCES}

1. Wagstaff A, Watabane N. Socioeconomic inequalities in child malnutrition in the developing world. Washington, D.C.: World Bank; 2000.

2. Smith I, Haddad I. Overcoming child malnutrition in developing countries: past achievements and future choices. Washington, D.C.: International Food Policy Research Institute; 2000.

3. Semba $R$, Bloem $M$, eds. Nutrition and health in developing countries. Totowa, New Jersey, United States of America: Humana Press; 2001.

4. de Onis M, Frongillo E, Blössner M. Is malnutrition declining? An analysis of changes in levels of child malnutrition since 1980. Bull World Health Organ 2000;78(10):1222-1233.

5. Londoño L. Poverty, inequality and human capital development in Latin America, 1950-2025. Washington, D.C.: World Bank; 1996.

6. United Nations Economic Commission for Latin America and the Caribbean. The equity gap: a second assessment. Santiago de Chile: ECLAC; 2000.

7. Macro International Inc. Demographic and Health Survey (DHS), Colombia,
1995 [electronic database]. Available from: http://www.measuredhs.com. Accessed 29 February 2000.

8. Macro International Inc. Demographic and Health Survey (DHS), Peru, 1996 [electronic database]. Available from: http://www.measuredhs.com. Accessed 29 February 2000.

9. Macro International Inc. Demographic and Health Survey (DHS), Bolivia, 1997 [electronic database]. Available from: http://www.measuredhs.com. Accessed 29 February 2000

10. World Bank, Instituto Nacional de Estadísticas y Censos. Living Standard Measurement Survey, Ecuador, 1998 [survey database]. Washington, D.C.: World Bank; 1999.

11. Van de Geer J. Multivariate analysis of categorical data: theory. London: Sage; 1993.

12. Van de Geer J. Multivariate analysis of categorical data: applications. London: Sage; 1993.

13. Meulman J, Heiser W. SPSS Categories 10.0. Chicago, Illinois, United States of America: SPSS; 1999.
14. Meulman J. Optimal scaling methods for multivariate categorical data analysis. Leiden: Leiden University, 2000.

15. United Nations Development Program. Human development report. New York: Oxford University Press; 2001.

16. Macro International Inc. Demographic and Health Survey (DHS), Guatemala, 1998 [electronic database]. Available from: http://www.measuredhs.com. Accessed 29 February 2000.

17. Macro International Inc. Demographic and Health Survey (DHS), Haiti, 1994 [electronic database]. Available from: http://www.measuredhs.com. Accessed 29 February 2000.

18. Kawachi I, Berkman L. Social epidemiology. New York: Oxford University Press; 2000.

19. Thorp R. Economic management and economic development in Peru and Colombia. London: Macmillan; 1991.

20. Larrea C, Freire W, Lutter C. Equidad desde el principio: situación nutricional de los niños ecuatorianos. Washington D.C.: Organización Panamericana de la Salud; 2001. 
RESUMEN Objetivo. Analizar los efectos de las condiciones socioeconómicas, regionales y étnicas en la desnutrición crónica en Bolivia, Colombia, Ecuador y Perú.

Métodos. El estudio se basó en las Encuestas Demográficas y de Salud de Colombia (1995), Perú (1996) y Bolivia (1997), y en la Encuesta de Condiciones de Vida de Ecuador (1998). Se creó un índice del estatus socioeconómico familiar, empleando un análisis categórico de componentes principales. La prevalencia del retraso del crecimiento se desagregó por estatus socioeconómico, etnia, lugar de residencia (grandes ciudades, pequeñas ciudades, pueblos y zonas rurales) y región (regiones montañosas frente al resto del país). Se aplicaron curvas de regresión suavizadas y funciones lineales para analizar los efectos del estatus socioeconómico en el retraso del crecimiento, creándose modelos específicos para Bolivia, Ecuador y Perú.

Resultados. Bolivia, Ecuador y Perú presentaron características similares: alta prevalencia general de retraso del crecimiento, mayor prevalencia en las zonas montañosas, sobre todo en las poblaciones indígenas, y fuertes disparidades socioeconómicas. Colombia, por el contrario, presentó menor prevalencia y menores disparidades regionales. Hubo un marcado gradiente socioeconómico del retraso del crecimiento en los cuatro países, siendo las tasas de prevalencia por lo menos tres veces mayores en los deciles más pobres que en el decil más alto.

Conclusiones. El marcado contraste entre Bolivia, Ecuador y Perú, por un lado, y Colombia por el otro, puede deberse a factores étnicos específicos que afectan a la población indígena, a las características peculiares de la dieta en las regiones montañosas, con escasas proteínas y micronutrientes, y a las diferencias entre las vías de desarrollo económico y social a largo plazo de los países. Junto con el marcado gradiente socieconómico observado en los cuatro países, el peso de los factores étnicos y regionales señala la necesidad de reducir la desigualdad, así como de mejorar globalmente la educación y el alojamiento, dirigir mejor los programas de salud y nutrición, y poner en práctica programas de participación integrados en las culturas indígenas.

\title{
9th Annual Canadian Conference on International Health Poverty, Health, and Equity: From Global Challenges to Innovative Solutions
}

\author{
Dates: $\quad 27-30$ October 2002 \\ Location: Crowne Plaza Hotel \\ Ottawa, Ontario, Canada
}

The 9th Annual Canadian Conference on International Health $(\mathrm{CCIH})$ will provide a forum to share knowledge and experience and to promote innovation and collaborative action. Each day's plenary session will focus on a different theme. Day 1 will concentrate on challenges, Day 2 on research, and Day 3 on innovation and action. In addition, this year's CCIH will offer three streams running all three days of the conference. The capacity-building stream will feature workshops and symposia aimed at knowledge and skills transfer. The knowledge-development stream will include a variety of papers and presentations on topics such as research with developing countries, using appropriate and innovative methodologies, and evidence-based decision-making. The action stream will feature papers, presentations, and workshops on innovative programs, projects, and policy-related activities with disadvantaged groups in the developed and developing world. Among the speakers confirmed for the conference are Mira Shiva, Mary Ann Lansang, Allan Bernstein, and Gerry Barr.

The meeting is intended for practitioners, researchers, educators, policymakers, and other persons who are interested in health and development issues.

The conference fee is Can $\$ 400$ (about US\$ 261) for early registration by CSIH members and Can\$ 500 (about US\$ 326) for nonmembers. The deadline for early registrations is 20 September 2002. After that date, the respective fees are Can\$ 475 and Can\$ 575. There are large discounts available for students, and persons can also register for and pay to attend just one day of the meeting.

\author{
Information: \\ Canadian Society for International Health \\ 1 Nicholas Street, Suite 1105 \\ Ottawa, Ontario, \\ Canada K1N 7B7 \\ Telephone: (613) 241-5785, extension 313 \\ Fax: (613) 241-3845 \\ E-mail: csih@csih.org \\ Internet: http://www.csih.org
}

